\title{
A New "Offline + Online" Teaching Model of College English Based on Cloud Computing
}

\author{
Wenzheng Wei \\ Anyang Preschool Education College, Anyang, Henan, China
}

\begin{abstract}
:
Cloud computing is a new platform for Contemporary College Students' English education. It is based on the construction of theory, cooperative learning and learning community, and is of great help to improve the quality of College Students' English teaching. This paper analyzes and discusses the College English teaching model based on cloud computing. The ecological teaching mode based on cloud computing platform combines cloud computing with ecological teaching concept, which can help teachers abandon the traditional filling teaching mode. The platform can support autonomous learning and meet the requirements of students' personality development. The experimental results show that cloud computing has good openness and sharing. Through cloud computing, the "co construction, sharing and sharing" of high-quality teaching resources can be realized. This method can achieve the balance of educational resources and inject new vitality into the traditional means of College English teaching.
\end{abstract}

Keywords: Cloud Computing, Construction Theory, College English, Teaching Ecology.

\section{INTRODUCTION}

As an Internet-based computing method, the core idea of cloud computing is the centralized sharing of resources [1]. It concentrates all resources on the network, integrates and manages them, and then provides these resources to users in the form of services. The characteristics of cloud computing enable users to use their resources without installing various applications, as long as they can access them through the browser. At present, cloud computing has entered the field of education and become an important auxiliary means of current teaching [2]. In the past decade, the rapid development of broadband and wireless network technology has promoted the use of wireless applications in our daily life. At the same time, various embedded and visual devices and corresponding software are developed and connected to the Internet by wireless. This new Internet accessible environment is called pervasive computing environment, and its 
Article History: Received: 28 October 2021 Revised: 05 December 2021 Accepted: 10 January 2022 Publication: 28 February 2022

ubiquitous network is also called ubiquitous network. Due to the characteristics of pervasive computing and ubiquitous network technology, it has been introduced into the current field of education, which is called ubiquitous learning in academic circles.

With the globalization of social economy, frequent foreign trade, tourism and academic activities make the use of English higher and higher. Therefore, English is not only one of the most common languages in the world, but also an important foreign language for many non English speaking countries. Therefore, how to use the technical characteristics of cloud computing to further improve students' English listening, speaking, reading and writing ability is very important. How to explore the effective use of cloud computing to increase the opportunities of English learning and practice, so as to improve the effectiveness and motivation of students' English learning, is an important topic in the current research. Starting with the actual questionnaire survey, this paper first puts forward the problems existing in the current college English teaching and the situation of students' autonomous learning, and then analyzes the data of the questionnaire survey results. The author puts forward the necessity of introducing College English ubiquitous learning in the current cloud technology environment.

\section{CURRENT RESEARCH STATUS OF CLOUD LEARNING}

In recent years, with the development of wireless network technology and communication technology, many scholars have focused on cloud computing and ubiquitous learning. Hwang et al. [3] applied the context aware ubiquitous learning environment to single crystal X-ray diffraction experiments. Because of its systematicness, authenticity and low cost, it can be applied to other complex scientific experiments. Huang et al. [4] believe that if ubiquitous learning can be effectively developed and used in education, its premise is to design a meaningful learning model. LAN et al. [5] believe that ubiquitous learning conditions help learners cooperate with each other and apply it to English reading courses in primary schools. Liu et al. [6] investigated how ubiquitous games affect English learning effectiveness and learning motivation through context cognitive learning environment. Hsieh et al. [7] proposed that in the ubiquitous learning environment, the learning mode should be combined with learning methods, tools and students' cognitive style. According to the activity theory, Liaw et al. [8] believe that the acceptance of ubiquitous learning can help individuals manage knowledge. Zhou Wenjuan [9] believes that the traditional language learning classroom based on class and curriculum will be severely challenged by cloud technology and ubiquitous learning, puts forward the research idea of English ubiquitous learning mode and learning resources based on cloud technology, analyzes it from the perspective of "cloud" resources, and discusses the ecological context of ubiquitous learning and the corresponding role orientation of teachers. Xue Wenfeng [10] believes that using the technical advantages of cloud computing can be applied to computer-aided College English teaching. Lin Shubing et al. discussed in 
Article History: Received: 28 October 2021 Revised: 05 December 2021 Accepted: 10 January 2022 Publication: 28 February 2022

detail the application of microblog in teaching. Zhou Yun applied microblog to college oral English teaching, which opened a new teaching mode. Fu Daoming et al. investigated and analyzed the knowledge sharing of microblog in ubiquitous learning, drew research conclusions and affirmed its role. Tan Wei emphasized students' autonomy in learning and the need to be good at using media networks when elaborating effective English teaching strategies. Wang Fucheng analyzed the application of cloud computing in college autonomous learning system from the perspective of technical feasibility.

At present, many colleges and universities have adopted the teaching mode of "classroom teaching + network autonomous learning", but the lack of understanding and understanding of the new college English teaching mode will inevitably lead to deviations in the process of practice. In classroom teaching, some teachers pay more attention to the technical level of PPT courseware making, ignoring the design of the actual teaching content in the courseware. To some extent, the courseware is an "empty shell without pulp"; Some teachers rely too much on multimedia means such as PPT in class, blindly read courseware, lack effective communication with students, and students can't grasp the focus of the course; Some teachers unilaterally pursue the teaching concept of "student-centered", set up a large number of classroom activities, and ignore the teaching of language knowledge.

In terms of online self-regulated learning, the online teaching platform purchased by some colleges and universities has outdated content and single form, which can not meet the needs of students' self-regulated learning. On the other hand, the lack of effective monitoring is also a major problem in network autonomous learning. The attendance rate of students is low, and the difficult problems they encounter in learning can not be solved in time. Over time, students' enthusiasm decreases, and autonomous learning also floats in the form. Although most colleges and universities have implemented the evaluation method of combining process evaluation and summative evaluation, but "foreign language teaching evaluation is lack of scientificity", "at present, the structure of College English evaluation is not reasonable and the operation does not meet the requirements of evaluation. It is necessary to build a scientific evaluation system according to the principles of evaluation", The following problems need to be solved urgently: the proportion of process evaluation and final evaluation; Diversification of process assessment; Improve the participation of middle school students. It can be seen that the current college English teaching reform needs further exploration and practice.

\section{CLOUD COMPUTING BASED WEB MINING TECHNOLOGY}

Although Web Mining and data mining are related, they belong to different concepts. Data mining was formally proposed at the 11th International Joint Artificial Intelligence Conference in 1989. It refers to the process of discovering useful knowledge and rules from a large number of incomplete, noisy, fuzzy and random data and information. It is a process of building models 
Article History: Received: 28 October 2021 Revised: 05 December 2021 Accepted: 10 January 2022 Publication: 28 February 2022

and discovering the relationship between data in large-scale massive data by using various analysis methods and tools. These models and relationships can be used to make decisions and predictions. In recent years, data mining has been widely used in government decision-making, enterprise management, marketing, medical and health financial services, university management and other fields. Web mining is a technology that applies data mining technology to the use of Web site resources and automatically discovers and extracts information and knowledge from Web documents and services. It uses data mining algorithms such as qualitative induction, classification learning, association rule mining, clustering analysis, etc., to extract interesting and useful patterns and other hidden information from related resources and users' browsing behaviors. According to different mining objects, Web data mining can be divided into three types: Web content mining, Web structure mining and Web usage mining [10] (Fig. 1).

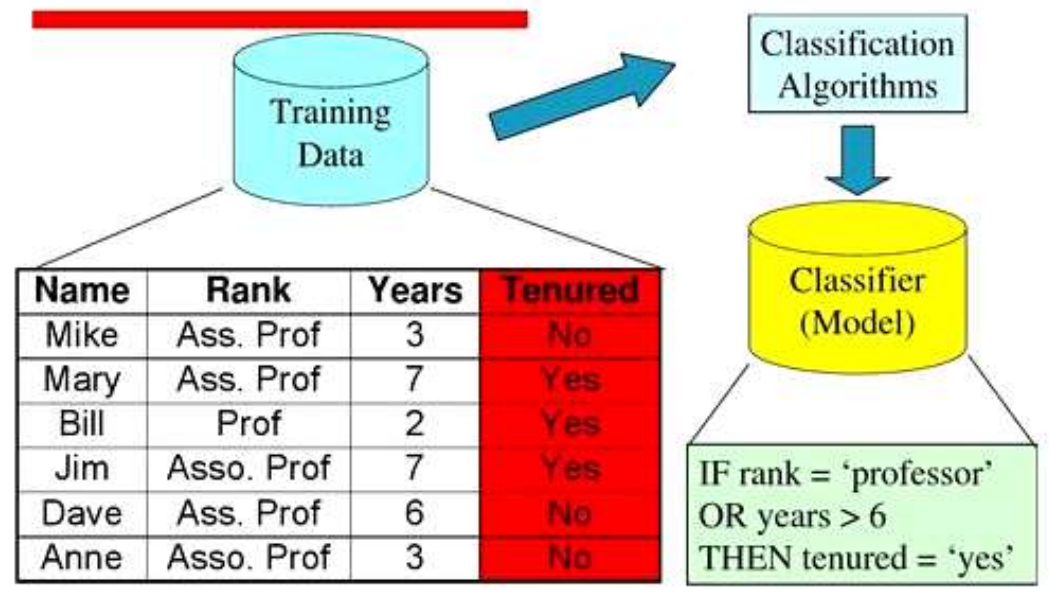

Figure $1 \mathrm{Web}$ mining classification

In short, Web mining technology is easy to use, does not need users to provide subjective evaluation information, it can deal with large-scale data and dynamically obtain user access patterns. Through the analysis of the user's visit content, stay time and frequency, we can get the knowledge about the learners' access interest and access pattern characteristics. According to the characteristics of these users, the Web site can dynamically recommend teaching resources for learners and provide them with links to the content they care about. This technology is used in the field of courseware construction, which can collect, track and analyze the learning information of online learners, and truly realize personalized and customized learning.

The difference between traditional teaching environment and individualized teaching environment lies in the intermediate link, which can be clearly seen through the comparison between Figure 2 and Figure 3 . In the personalized environment, the learning platform of the middle layer has been expanded. The individualized scheme can establish a personalized learning mode according to the characteristics of learners. The learning platform records the user's access, reorganizes the Web access transaction model, and obtains the Web access transaction library. The frequent itemsets are generated by mining Web access transaction 
Article History: Received: 28 October 2021 Revised: 05 December 2021 Accepted: 10 January 2022 Publication: 28 February 2022

database and stored in the knowledge base. After that, the personalized recommendation module extracts the current user's access sequence, matches the frequent patterns in the knowledge base, and then recommends the qualified teaching resources to the learners according to the association principle. Different learners will have different behaviors when using the resource database. Personalized service is to provide different services to users according to the characteristics of different users. The main work is to efficiently obtain useful information from massive data to meet the personalized needs of different users. The personalized network resource library provides each learner with learning resources that adapt to their needs and characteristics, and automatically adjusts the content of the resources, making learners feel that the whole teaching system is specially customized for them.

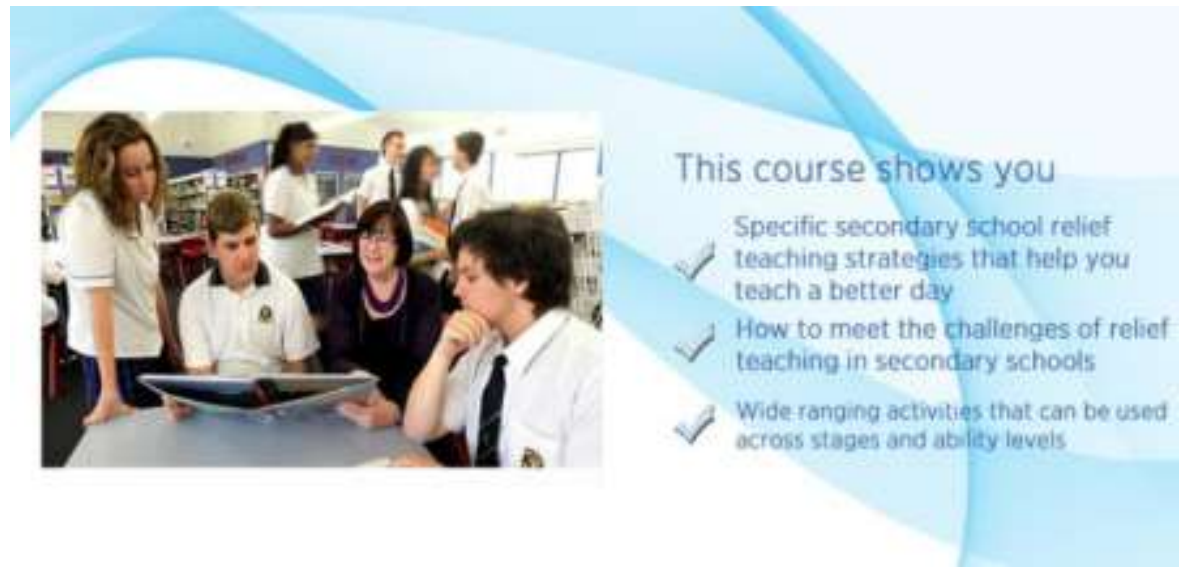

Figure 2 Traditional online teaching environment

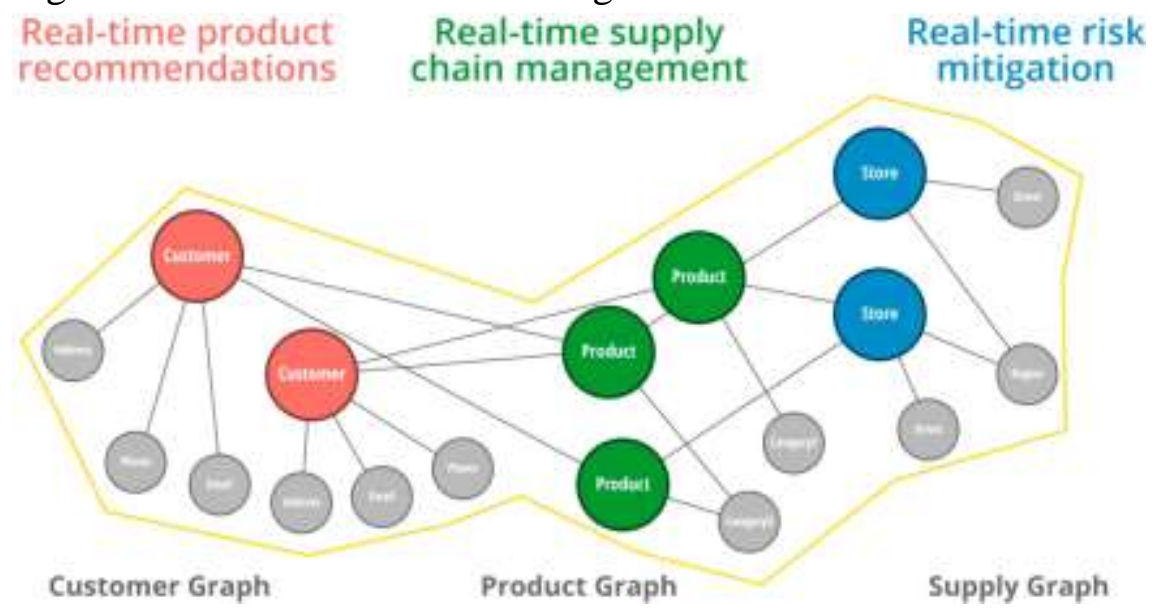

Figure 3 Personalized online teaching environment

Furthermore, the personalized service platform provides learners with teaching resources that meet their personal interests. With the changes or shifts of learners' interests, the system can automatically track these changes and adjust the contents of teaching resources. In this way, learners' learning interests will be mobilized, and the system will automatically provide them with targeted teaching resources that dynamically match the learning interests of scholars. 
Article History: Received: 28 October 2021 Revised: 05 December 2021 Accepted: 10 January 2022 Publication: 28 February 2022

Resources will really "live".

Figure 4 shows the key technologies in personalized recommendation of online learning. The personalized online teaching platform of English grammar course is the key technology based on Web mining. Through information collection and analysis of learners' learning habits and usage patterns, it predicts their future use patterns, provides corresponding personalized resources, and realizes the dynamic customization of teaching resources.

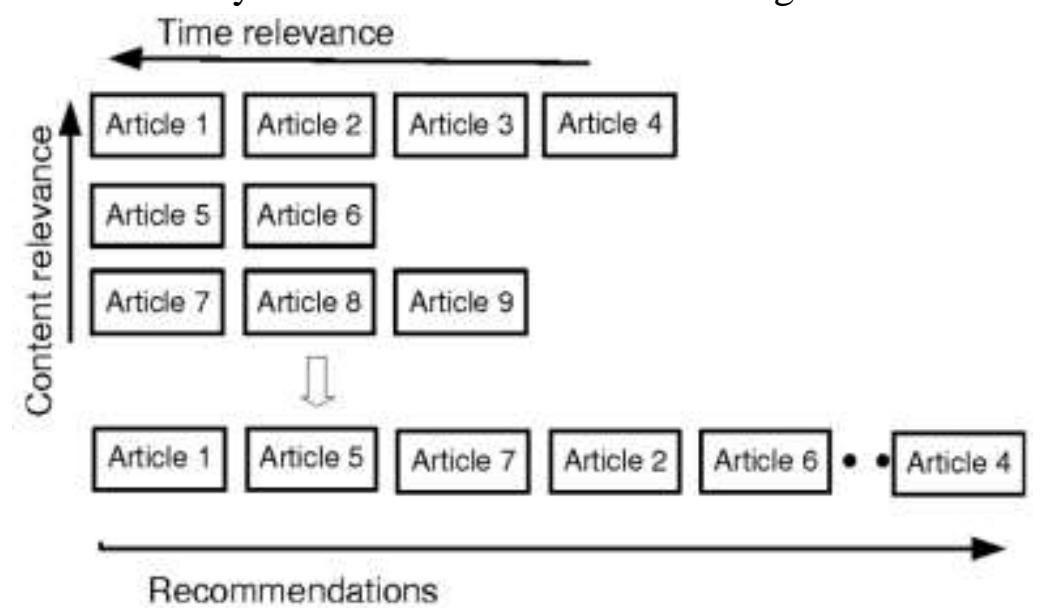

Figure 4 Personalized recommendation process

\section{CLOUD COMPUTING BASED COLLEGE ENGLISH TEACHING MEASURES}

At present, students are not only satisfied with classroom teaching, but also want to meet their own learning needs. Therefore, extracurricular autonomous learning will highlight its importance. In addition, making full use of the Internet for autonomous learning is easier to cultivate professional + English compound talents. In the learning environment of cloud computing, students get rid of the unified teaching content and teaching mode in the classroom. Students only need to $\log$ in to their website through the network, and then they can purposefully choose the content to learn according to the needs of their own knowledge structure. It makes students' autonomous learning possible. Because cloud computing stores data in the cloud and implements unified management and distribution, students can use resources to learn anytime and anywhere, without being limited by the lack of learning materials at hand. Cloud learning provides rich learning resources and information. For questions you don't understand, you can get answers effectively and quickly, and reduce the number of students' inquiries. At the same time, students can communicate professionally or non professionally with students, teachers and experts all over the world in English, get rid of the dilemma that teachers need answers to get answers, not only improve their professional knowledge, but also improve their English level, form a good habit of thinking in English, and improve their social skills. 
Article History: Received: 28 October 2021 Revised: 05 December 2021 Accepted: 10 January 2022 Publication: 28 February 2022

According to the specific context, the rich resources of cloud learning can provide support for students' personalized learning. In addition, in the cloud learning environment, students can more control their learning process and adjust the learning content according to everyone's learning situation, so as to get rid of the unified teaching content and progress in the traditional classroom. From the perspective of feasibility, the current college English cloud learning platforms are mainly divided into two categories: one is the cloud learning platform independently built by colleges and universities, and the other is the cloud learning platform provided by publishing houses. However, from the analysis of the current actual situation, it is not a small financial and technical challenge to require all schools to adopt cloud computing. Therefore, the author believes that we can gradually transition from the cloud computing platform provided by the publishing house to the cloud learning platform of colleges and universities. The cloud learning platform provided by the publishing house is characterized by low price or even free, and its teaching platform, resources and courseware are well made and easy to use. However, the cloud learning platform provided by the publishing house is limited to its own published teaching materials, which is not conducive to students' autonomous learning. Therefore, teachers can provide various English learning resources through QQ, microblog, blog and other network tools to make up for their shortcomings. Because the cloud learning platform provided by the publishing house has some shortcomings, the author believes that the cloud computing platform really suitable for autonomous learning should add the existing educational information resources of multiple schools to a "cloud". In recent years, schools, educational institutions and related enterprises have invested a lot of funds and resources in the information construction of education. Therefore, the application of cloud computing in the field of education can realize the sharing of teaching resources. Technically, this way can reduce the capital and time investment of a single institution, and realize the real resource sharing. However, the second method has a relatively long implementation time cycle. Therefore, the author believes that on the premise that the technical and financial conditions are not mature, the first method can be adopted first, and then gradually transition to the second method.

With the rapid development of wireless network technology, mobile phones, tablets and other mobile devices can easily access the Internet. Mobile phones are no longer limited to the traditional function of calling and sending text messages. More and more people use mobile phones to surf the Internet and other functions. Mobile Internet has become one of the activities that students engage in every day. At least $50 \%$ of students use mobile phones to surf the Internet for at least 4 hours every day. In addition, most students use mobile phones to surf the Internet more than computers. This provides a good condition for ubiquitous learning.

Mobile Internet has several advantages: Mobile Internet can provide personalized connection; It can improve the cooperation of real-time interaction; It can realize the positioning function of users. These benefits can improve the traditional learning environment. In addition, 
Article History: Received: 28 October 2021 Revised: 05 December 2021 Accepted: 10 January 2022 Publication: 28 February 2022

mobile devices can also be used to improve learning efficiency. First of all, the portable mobile device gets rid of the geographical restrictions that the traditional learning must be in the classroom or library, so that students can learn anywhere. Secondly, the interactivity of mobile devices makes it possible to cooperate with others; Third, mobile devices can help students get the latest data in real time. Therefore, ubiquitous learning provides a good language environment for English learning. Ubiquitous learning makes use of rich network resources to obtain any information needed at any time and anywhere, so that it can use nearby mobile devices anytime and anywhere to learn according to its own needs. Through ubiquitous learning, students can incorporate the process of English learning into their daily life. The real context is more conducive to the improvement of students' English listening, speaking, reading and writing ability. Learning in real context and scene makes up for the defect of unreal context in traditional college English classroom teaching. The personalized, interactive and real-time characteristics of mobile Internet combined with ubiquitous learning make students' learning not limited by the traditional classroom learning mode. Students can customize their own college English autonomous learning mode and content according to their own learning objectives.

\section{CONCLUSION}

Cloud computing is a hot spot in the current development of science and technology. At the same time, it can also promote the development of educational technology. The characteristics of ubiquitous learning environment create a flexible learning environment, which can meet the requirements of different learning activities. Ubiquitous learning based on cloud technology will have a great impact on traditional education. Reasonably and effectively integrating cloud learning and ubiquitous learning can make up for the defects in traditional classroom teaching, enhance the purpose of students' autonomous learning and meet students' personalized learning needs.

\section{REFERENCES}

1. Artés, J., Pedraja-Chaparro, F., \& Salinas-Jiménez, M. D. M. (2017). Research performance and teaching quality in the spanish higher education system: evidence from a medium-sized university. Research Policy, 46(1), 19-29.

2. Bucher, B. T., Duggan, E. M., Grubb, P. H., France, D. J., Lally, K. P., \& Blakely, M. L. (2016). Does the american college of surgeons national surgical quality improvement program pediatric provide actionable quality improvement data for surgical neonates? Journal of Pediatric Surgery, 51(9), 1440-1444. 
Article History: Received: 28 October 2021 Revised: 05 December 2021 Accepted: 10 January 2022 Publication: 28 February 2022

3. Butterworth, N., Steinberg, D., Müller, R. D., Williams, S., Merdith, A. S., \& Hardy, S. (2016). Tectonic environments of south american porphyry copper magmatism through time revealed by spatio - temporal data mining. Tectonics, 35.

4. Hsiao, H. S., Chang, C. S., Lin, C. Y., Chen, B., Wu, C. H., \& Lin, C. Y. (2016). The development and evaluation of listening and speaking diagnosis and remedial teaching system. British Journal of Educational Technology, 47(2), 372-389.

5. Lee, M., Lee, K., Yu, N., Jang, I., Choi, I., \& Kim, P., et al. (2017). Chimerdb 3.0: an enhanced database for fusion genes from cancer transcriptome and literature data mining. Nucleic Acids Research, 45(Database issue), D784-D789.

6. Lin, X., Hu, X., Hu, Q., \& Liu, Z. (2016). A social network analysis of teaching and research collaboration in a teachers' virtual learning community. British Journal of Educational Technology, 47(2), 302-319.

7. Malik, M. M., Abdallah, S., \& Ala' Raj, M. (2016). Data mining and predictive analytics applications for the delivery of healthcare services: a systematic literature review. Annals of Operations Research, 1-26.

8. Mathis, A., Schmidt, D. W., \& Medley, K. A. (2016). The influence of residency status on agonistic behavior of male and female ozark zigzag salamanders plethodon angusticlavius. American Midland Naturalist, 143(Jan 2000), 245-249.

9. Peng, Q. (2017). Optimization of physical education and teaching quality management based on bp neural network. Boletin Tecnico/technical Bulletin, 55(7), 643-649.

10. Price, L., Svensson, I., Borell, J., \& Richardson, J. T. E. (2017). The role of gender in students' ratings of teaching quality in computer science and environmental engineering. IEEE Transactions on Education, PP(99), 1-7. 